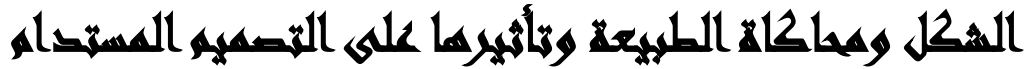

\section{[}
محسن عبد القادر الحناوي(')- حسن أحمد حسن يوسف(؟)-- هشام أحمد محمد صبح|(')

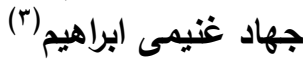

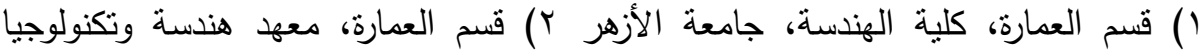
الطيران r) معهد طيبة العالى للهندسة كلية العندة

\section{المستخلهى}

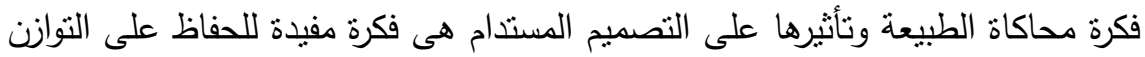

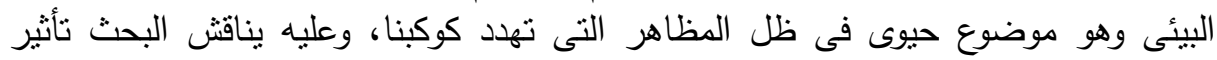

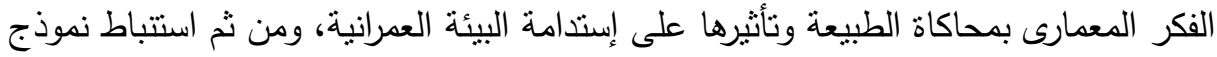

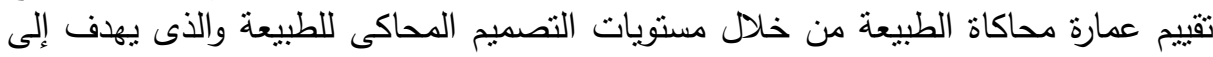

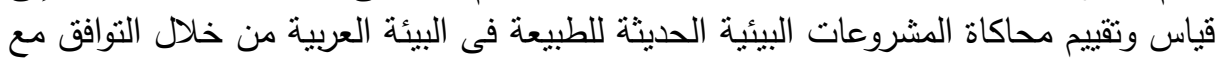

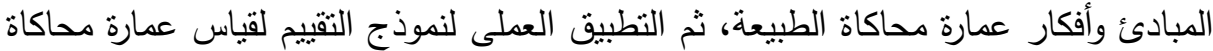

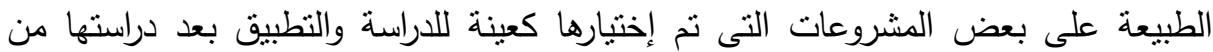

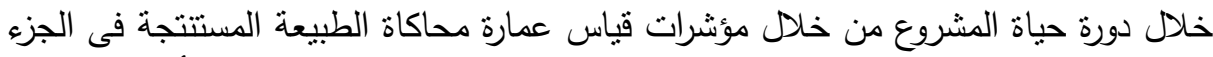

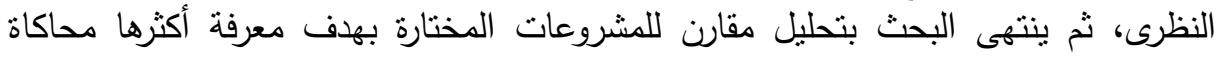
للطبيعة والاستفادة منه كنموذج قياس للمشروعات البنات البيئية فى المنطقة العربية.

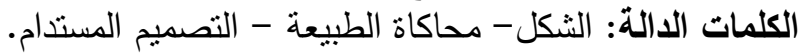

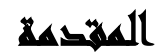

خلال العقود الثلاثة الماضية شهدت البيئة أزمات خطيرة كإستتفاذ الموارد غبر المتجددة، إضدحلال طبقة الأوزون والعديد من الظواهر الأخرى التى نتجت عن سوء إستخدام وإستغلال الإنسان لبيئته المحيطة، فبالرغم من التسارع العلمى والطفرات المتلاحقة وتعددية الإتجهات المعمارية المعاصرة المحلية والعالمية التى حاولت تحقيق أهداف الإستدامة ومنها إتجاهات

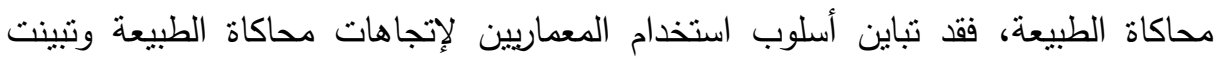
قدرتهم على فهم وتوظيف الدور الذى يُمكن من تحقيق محاكاة الطبيعة أن ينت تحقيق مبادئ

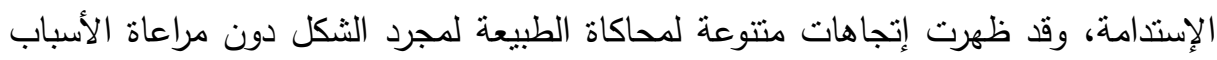

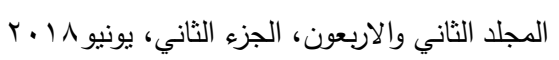


الحقيقية لدور الثكل فى الاستدامة، وبالتالى تم إستتساخ عمارة شكلية لاثُمت لمفهوم الطبيعة

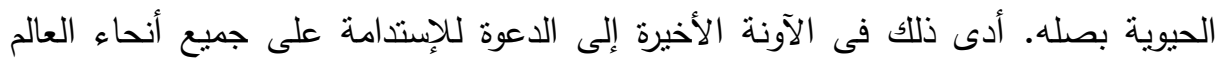

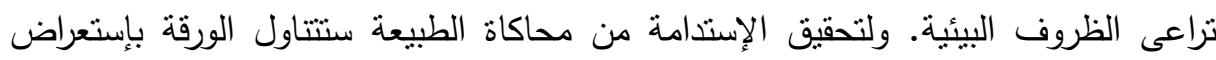

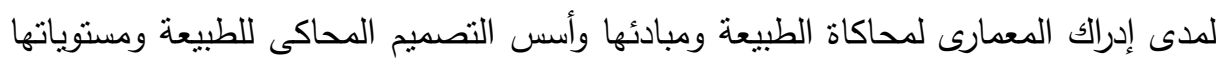
وإستتباط نموذج لتقييم المشروعات المعمارية التى التى حاكت الطبيعة فى مكوناتها تطبيقآ على البيئة العربية.

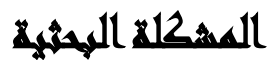

الحاجة إلى تحقيق مبدأ العمارة المستدامة من خلال محاكاة الطبيعة فى الاشكال أفرزت أنماطآ معمارية توافقت كنموذج تقليد الثكل دون تحقيق المضمون، الأمر الذى أدى إلى تقييم

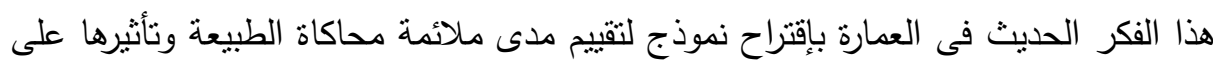
استدامة العمارة.

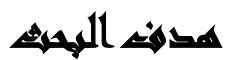

تصميم نموذج لتقييم وقياس مدى ملائمة الثكل بمحاكاة الطبيعة وتأثيرها على استدامة العمارة تطبيقآ على البيئة العربية.

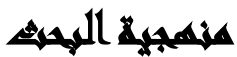

يمر البحث بثلاث خطوات:

الخطوة الأولى: استقراء شامل لإدراك النسان لمحاكاة الطبيعة والتعرف على مبادئها المختلفة

$$
\text { وأسسها ومستويات تقليدها. }
$$

الخطوة الثانية: استتباط نموذج قياس مقترح من مخرجات الخطوة الأولى لقياس محاكاة الشكل بالطبيعة ومحاولة تطبيقه على مشروع محلى وآخر دولى.

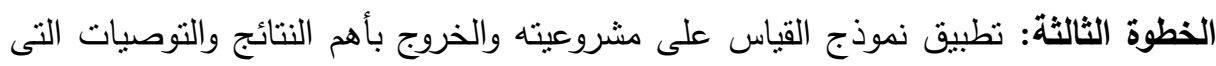
تعمل على إستدامة العمارة بمحاكاة الأشكال الطبيعية. 


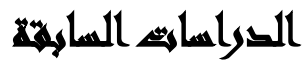

1. Amr F. Elgohary(2009) "Second Nature Architecture: A New Design Trend of EnvironmentalDesign" Ain ShamsJournal of Architecture and Urban Planning

فكرة تكنولوجيا عمارة محاكاة الطبيعة مطلوبة لانها تمس جزءا هاما من احتياجات

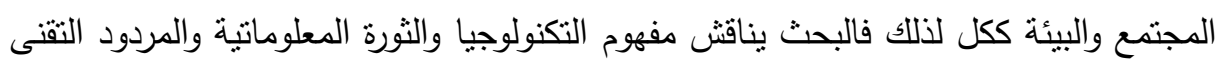

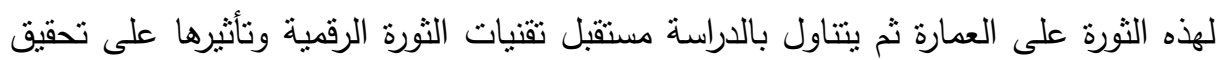
مبادئ واهداف عمارة محاكاة الطبيعة كاحد الاتجاهات الحديثة للعمارة البيئية.

\section{Steve Parnell 2012Designing the Future The EMBO Journal} فى ندوة كلية مانشستر للعمارة نم انعكاس التمدن والصناعة، فكتب ستيف بارنيل حقيقة

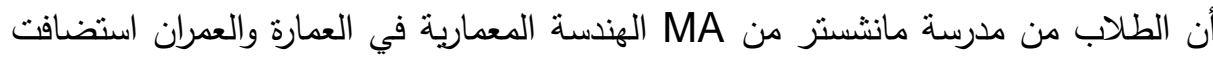

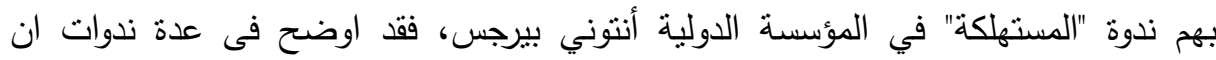

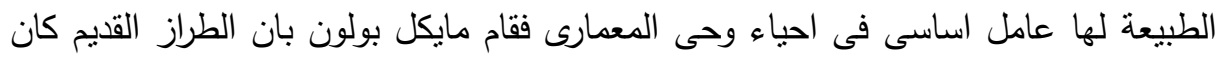

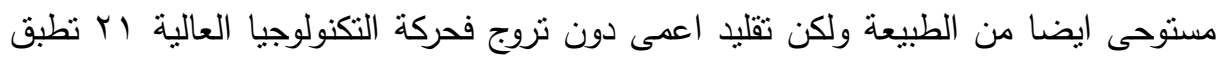

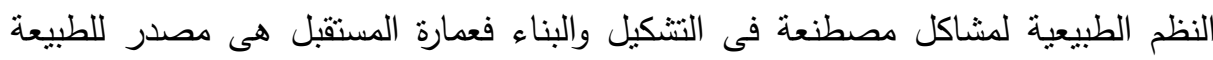

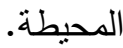

3. Ghonimi Ibrahim، Islam(2012)Architecture Manifestation of Natural Scientific Paradigm Shift International Journal of Architecture and Design, ISSN: 2051-5820,

يحدد البحث العلاقة بين الثورات العلمية وأثرها على نظرية مشابهة للهندسة المعمارية

المعاصرة على وجه الخصوص، فيستكثف منهجية الطرق التي ادت للتحولات النوعية في الاستكثاف العلمي للطبيعة وإعادة تشكيل مظهر الطبيعة والهندسة المعمارية وفقا لصياغة لغة العمارة. يتتبع الرجل الطبيعة منذ عبر التاريخ، والمهندسين المعماريين يعملوا جاهدين بشكل واضح لمحاولة فهمه لشكل الطبيعية. ولذلك فمن المهم تحديد مدى اختلاف ومبادئ التصميم التي هي مستمدة من النموذج الكلاسيكي العلمية عن تلك التي تعقد النموذج العلمي. يمكن تغيير النموذج العلمي زيادة وتعميق المعرفة العلمية للطبيعة. 
() إدرالك الإنسان لمحاكاة الطبيعة: قدمت الطبيعة هدية للعلم لأنها أثبتت جدارتها في الصمود بوجه الزمن فمرت الطبيعة بأزمات خطيرة متكاملة على طول عمرها ( ^,r مليار

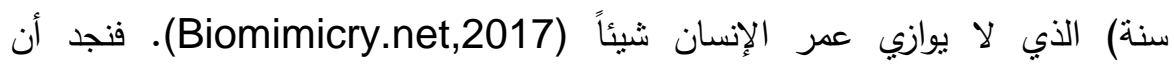
الكائنات الطبيعية تتفاعل مع البيئة لملايين السنين بطريقة ناجحة ومستدامة، دون أن النينان

$$
\text { تتلاشى الموارد الطبيعية أو تلوث البيئة. }
$$

على هذا ثقوم "محاكاة الطبيعة" لذلك يعتبر ^, ب الرقم الأساس في قضينتا هذه فهو شعار الدحاكاة وفيه كل تفاصيل تقليد الطبيعة فظهرت منظمة تقليد الطبيعة (؟,^) وسميت بهذا الكود نظراً لما سبق ذكره عن تجربة الأرض فى البقاء مع التطوير منذ ظهور أشكال

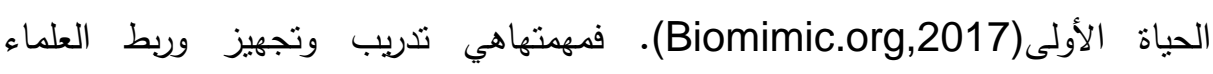
والمرندسين والمعماريين والمعلمين وغيرهم من المبدعين فى الطبيعة بوجه مستدام

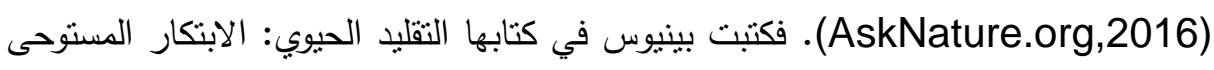
من الطبيعة" أنه مع الطبيعة، يوجد عالم مستدام بالفعل"، نحن بحاجة فقط لفتح أعيننا لروئية

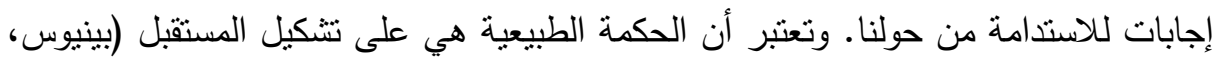

كان الإنسان البدائى واعى بالطبيعة فى إدارة حياته والحصول على منطلباتها وفقاً للمحيط الذى يعيش فى محتواه، فكان يتصرف بوعي مع الطبيعة بالرغم من بدائيته وتلقائيته

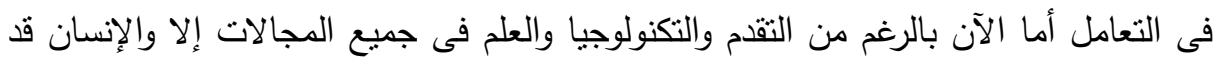
أغفل الطبيعة وأهمية الإرتباط بها ورعايتها وبدلاً من أن نساعد التكنولوجيا فى موائمة الطبيعة فبدأت تساعد فى اقتحام الطبيعة والتعدى عليها مما أدى إلى تدهورها ومن ثم تدهور الإنسان نفسه إلى أن ظهرت عمارة محاكاة الطبيعة فبدأت تهدف لتحقيق التكامل بين الإنسان وبيئته

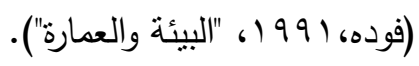




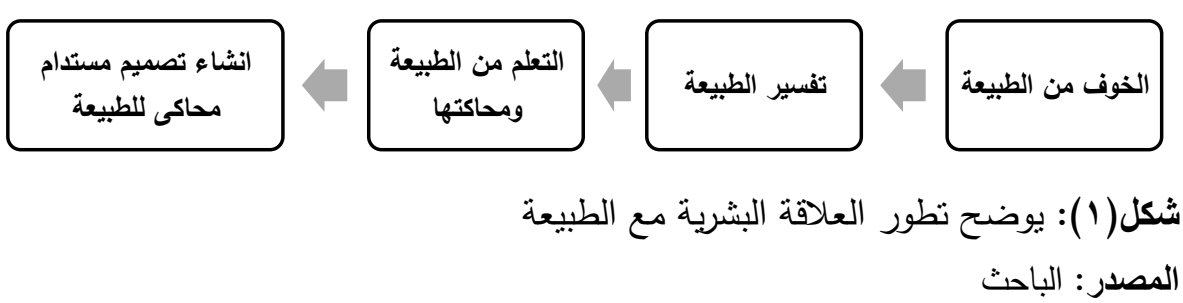

r مبادئ محاكاة الطبيعة: أعطانا الله الحكمة والإرادة للتعلم، وخلق الطبيعة لتكون معلمه من أجل البقاء على قيد الحياة على الأرض، فهى ليست مصدر للثروات

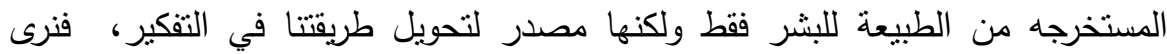
الطبيعة (كنموذج، كمقياس وكمعلم ) سوف تكون هذه الروئة مدخل أساسى لكى تقودنا لمحاكاتها بشكل صحيح.

نتيجة للتفاعل بين الإنسان والطبيعة نجد أن الطبيعة هى مصدر لإلهام الإنسان بشكل

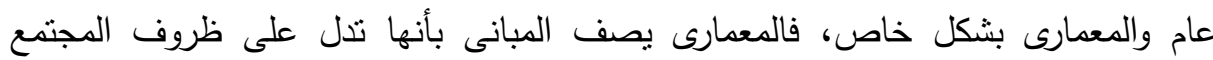
كوحدات منتمية للطبيعة تشكل الإمكانيات المحاكية للطبيعة بحيث تتفاعل بشكل متجدد ومستمر لنتعر الإنسان كأنه جزء من الطبيعة وليس دخيل بها فمن خلال تحديد القوى الطبيعية نم تحديد أول توجه للبناء عند الإنسان عن طريق ترجمة علاقته بالطبيعة إلى

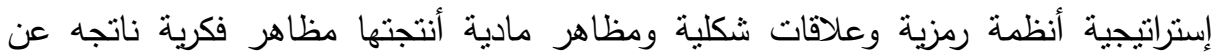

( Schulz, Christian , 1971 "Existence, Space التطلع للطبيعة فرنس Publishers, andArchitecture",NewYork,Prayer لمفهوم الطبيعة والعلاقات بين (الإنسان والطبيعة والعمارة) فيجد الباحث البعد النظرى لإتجاه

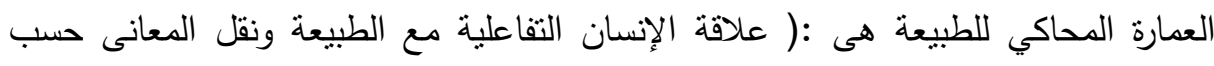
المواقف الفكرية الناتجه عن النطلع للبيئة المحيطه شاملة للأنظمة الثكلية والمظاهر المادية). أ) الطبيعة كنموذج: يعتمد الإنسان على سلوك الطبيعة فى التثكيل الحديث للتصميم، فنتقوم الطبيعة بدور مهم فى وعى الإنسان لإيجاد طرق جديدة لتطوير الحياة بالمستقبل، حيث أن لايوجد نفايات داخل الطبيعة بل بالعكس يوجد أنظمة متداخلة داخل النظام البيئى 
فيمكن إستخدام النفايات لكائنات كمنتجات ثانوية لإحتياجات كائنات أخرى فهذا يؤكد فكرة حل مشاكل الكائنات الحية بشكل مستدام، فمثلاً بإستخدام فضلات الحيوانات وبتهض التركيبات البسيطة مع الثمس ننتج مواد قابله للتحلل تستخدم فى التصميم الداخلى مثل بالتل

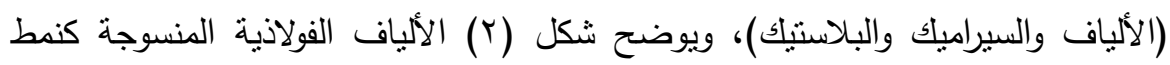

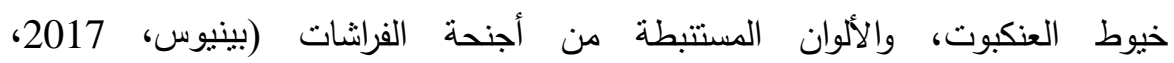

("Biomimicry: Innovation in-spired by nature"
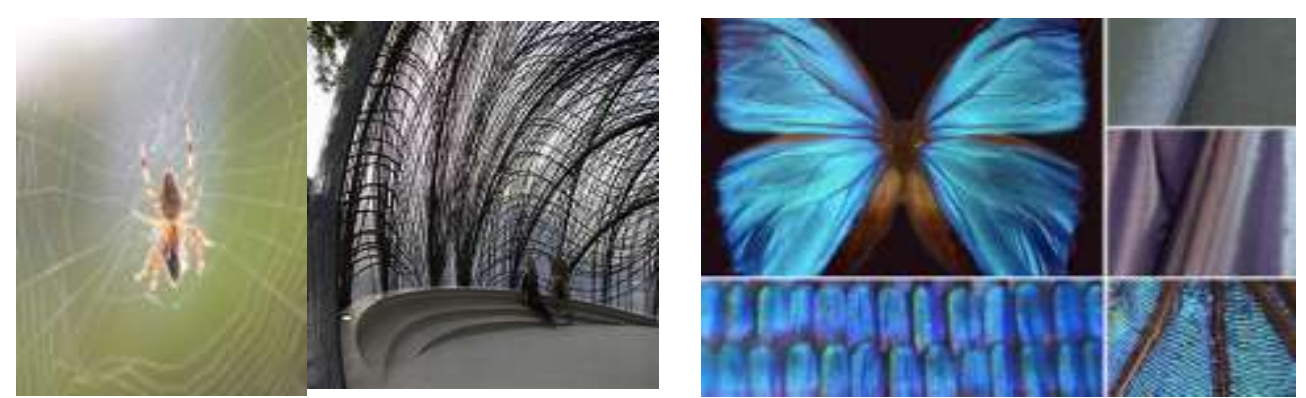

شكل(ץ): يوضح محاكاة المعمارى للألياف المنسوجة كنمط خبط العنكبوت وإستتباط الألوان الموجودة على أجنحة الفراثنات https://biomimicry.org - المصدر ب) الطبيعة كمقياس: يعتبر الإنسان البيئة هى المعيار الأساسى للحكم على صحة إبتكارتتا

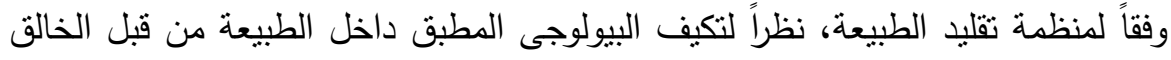

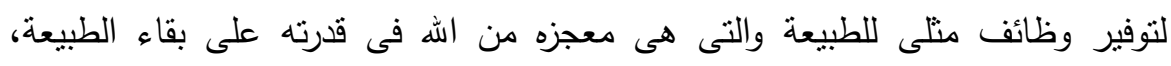

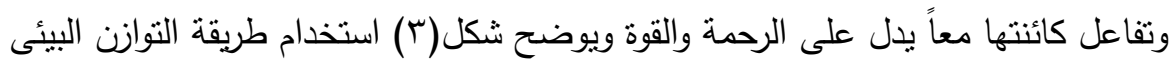

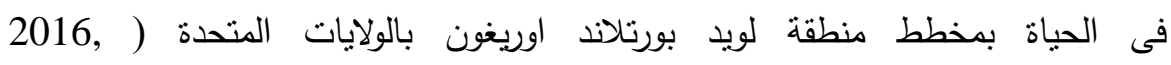
(http://scienceandquran.com 


\section{Water}

\section{Pre-development Water Use Conditions 2004 Existing Water Use Conditions}
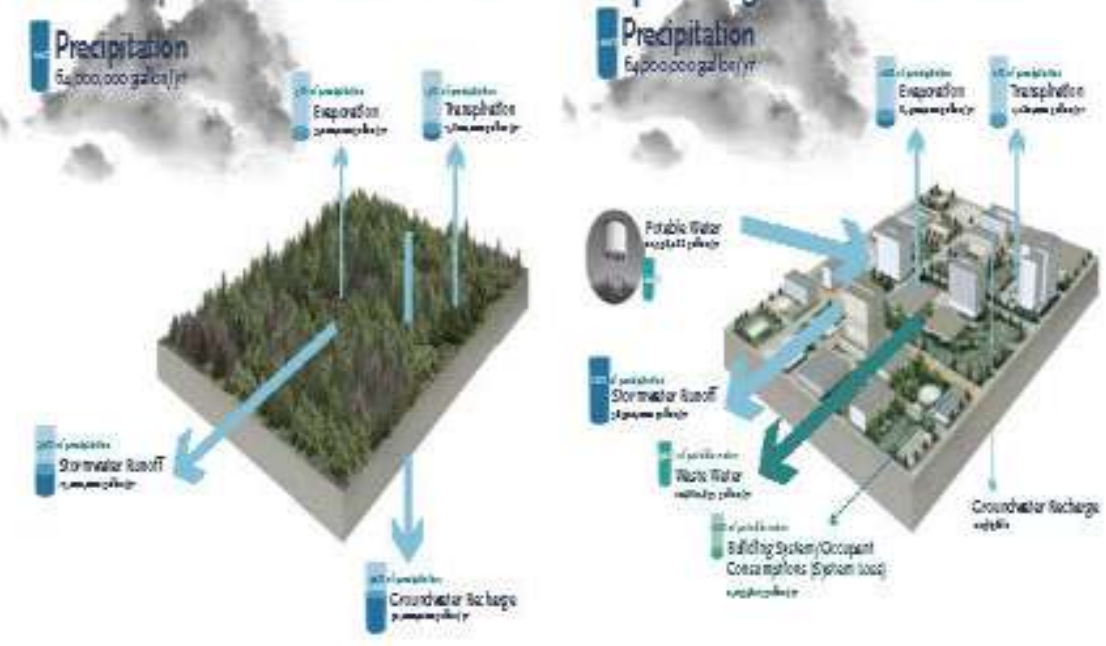

2050 Per Code W/ater Use Conditions

2050 Per Plan Water Use Conditions
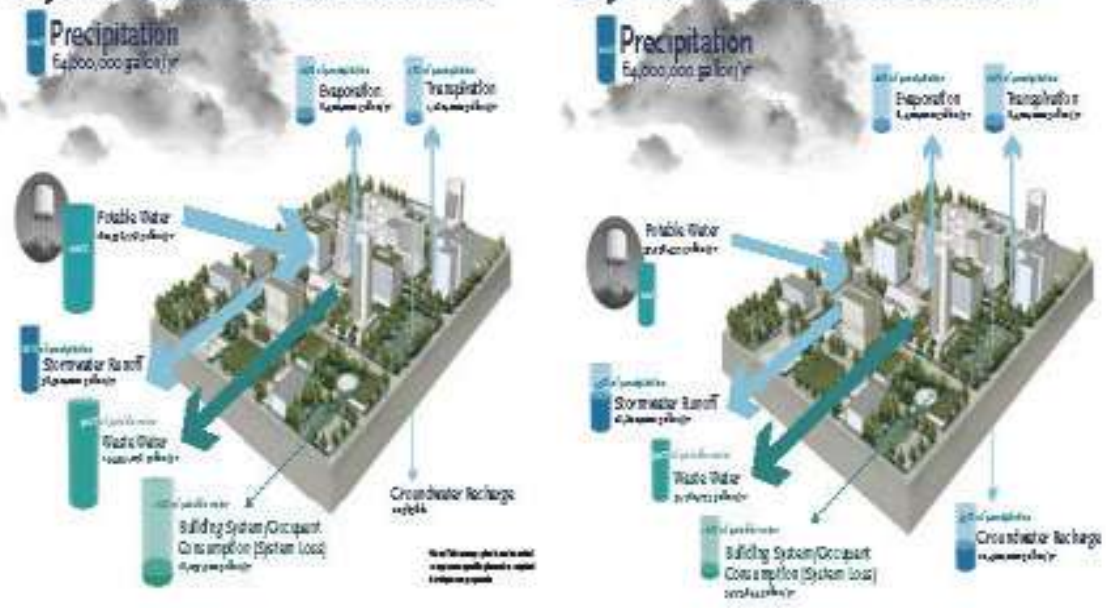

شكل(ץ): يوضح استخدام طريقة التوازن البيئى فى الحياة بمخطط ولاية بورتلاند اوريغون 


$$
\text { بالولايات المتحدة الامريكية }
$$

http://scienceandquran.com (2016)- المصدر:

ج- الطبيعة كمطم: توجد علاقة قوية بين النظام البيئى والبيئة البشرية حيث أن فكر الإنسان

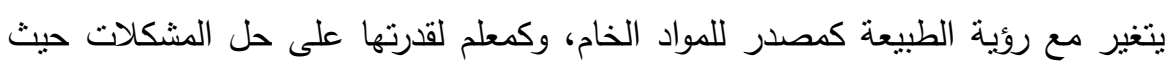

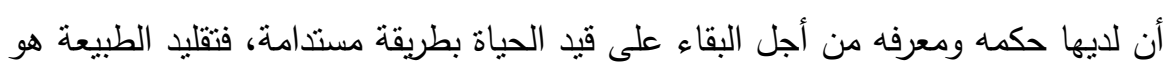

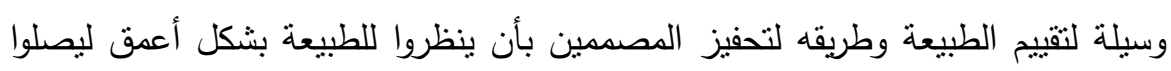

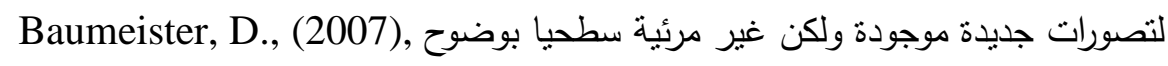
Bio-mimicry Presentation at the University of ،Washington College of Architecture" صورمختلفة لدحاكاةالطبيهة .Seattle, USA.
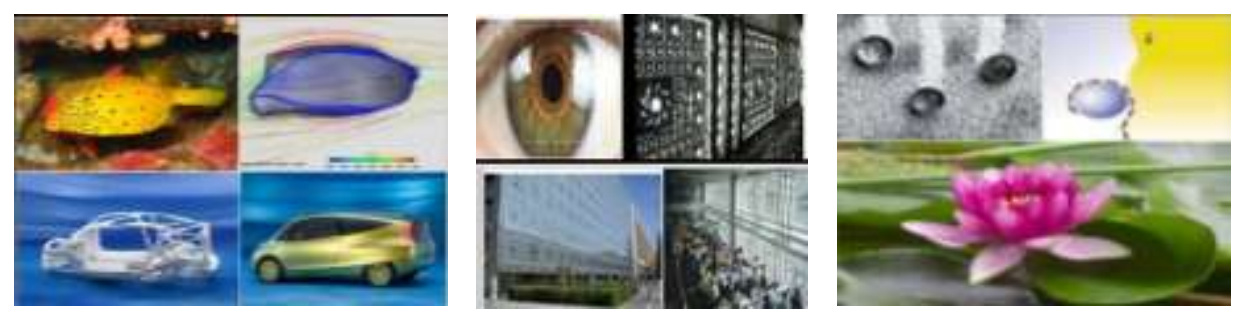

شكل(؟): محاكاة زهرة اللوتس شكل(ه): محاكة قرنية العين شكل(؟): محاكة هيكل السككه

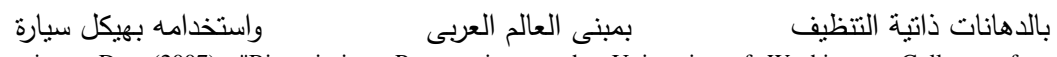
المصدر:- Baumeister, D. (2007), "Bio_mimicry Presentation at the University of Washington College of Seattle, USA. ‘Architecture"

r) أسس التصميم المحاكى للطبيعة: قدم معهذ تقليد الطبيعة أداتان مساعدتان لعملية تقليد الطبيعة منمنلة فى "عدسة التصميم "، كما هو موضح بشكل(V) والاتجاهات

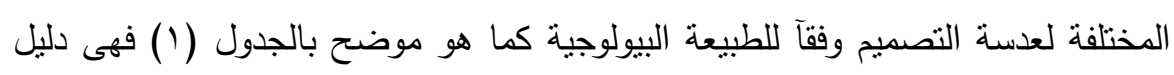
من سبع خطوات يساعد المصمح على النظر العميق لحل مشكلة بيولوجية بدل من تكرار

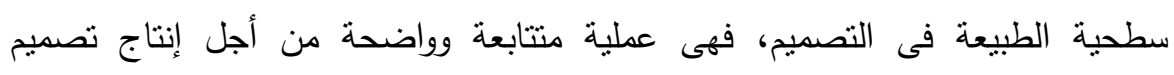
مستوحى من الطبيعة يستخدم حلول موجودة فى الطبيعة لحل مشكلات بطرق ابداعية

.(Biomimicry.net,2017)

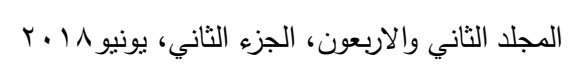




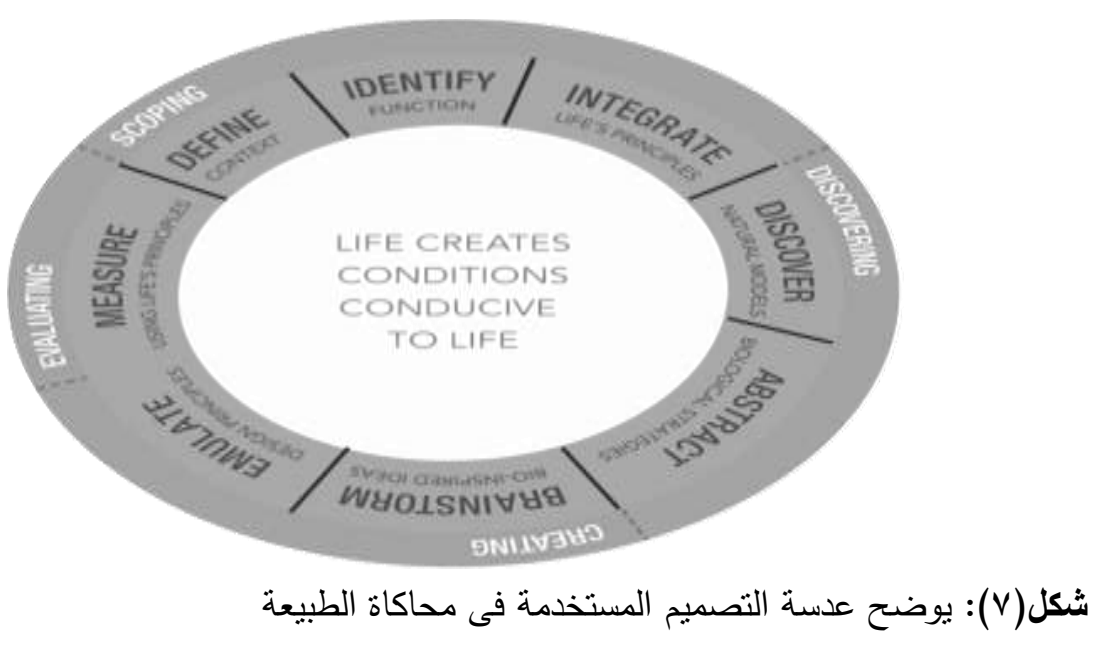

biomimicry.net المصدر

1-الخطوة الأولى (Identify)تحديد الوظيفة: تحديد جوهر المشكلة وطرح مواصفات التصميم لحلها ويتم ذلك من خلال تحديد الوظيفة الأساسية للتصميم.

r-الخطوة الثانية (INTEGRATE): تحدى الطبيعة البيولوجية: دراسة الطبيعة بيولوجيا فهل تقدر الطبيعة على فعل الوظيفة التى تم تحديدها لحل مشكلة ما؟ فأهم مايميز أداة حل المشكلة أنها تتطلب النظر لنتائج مختلفة من ^,ب مليار سنه من البحث والتطوير البيئي الذي حدث في الطبيعة لإنتاج نظم مستدامة معقدة، من خلال تحديد شروط محددة يتم بموجبها تحقيق وظيفة في الطبيعة مثل المناخ، المواد الغذائية، الظروف الاجنماعية

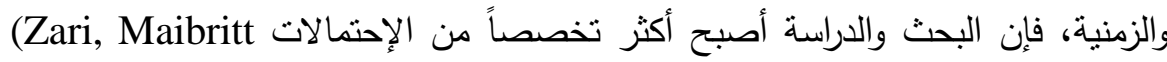
Pedersen(2009): Biomimetic approaches to Architectural design for increased Sustainability.

r-الخطوة الثالثة(Discover): إكتثاف الطبيعة البيولوجية: اكتثاف أمثلة ونماذج محددة من الحلول البيولوجية للمشكلة فتسعى الكائنات الحية فى تحدى تغيرات الطبيعة للبقاء على قيد الحياة ويوصى بالتعاون مع عالم الأحياء في هذه المرحلة للتقدم في المعرفة البيولوجية. 
ع-الخطوة الرابعة (Abstract): البحث عن أنماط وعمليات متكررة في الطبيعة تحقق النجاح فى الإستدامة والبقاء. والتي يمكن توضح جوهر الترابعة العمليات دون أن تهمل الظواهر

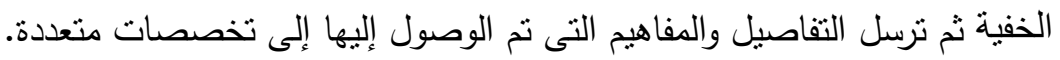

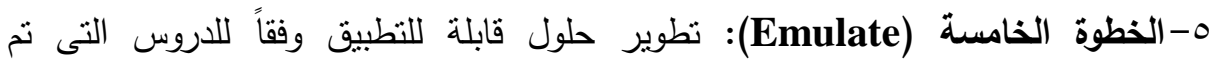

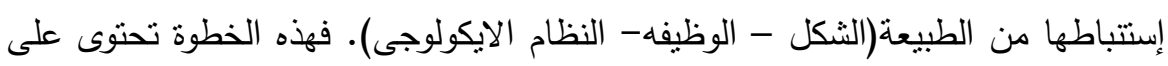

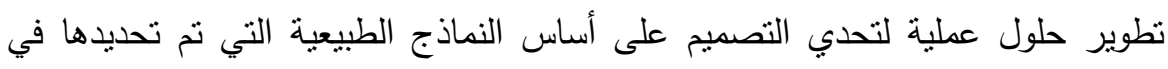
الخطوات السابقة. فالموقع عنصر قياس للحل فيجب أن يدرس بعناية لأنه عبارة عن

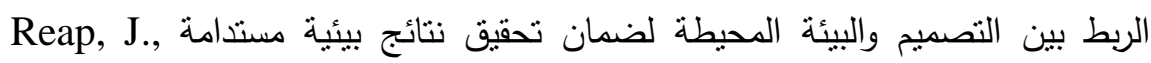
Baumeister, D. \& Bras, B. (2005) Holism, Biomimicry and Sustainable Engineering. ASME International Mechanical Engineering Conference and Exposition. Orlando, FL, USA. 1- الخطوة السادة(Evaluate): تقييم الحلول وفقاً لمبادئ الحياة فتحتوى هذه الخطوة على كيفية تقييم التصميم وفقاً أم ضد "مبادئ الحياة" عن طريق طرح أسئلة مثل "هل التصميم

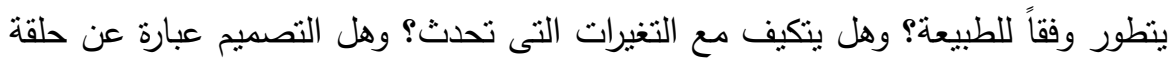
مغلقة(اكتقاء ذاتى)؟ من خلال هذه النقاط نصل لنتائج مستدامة. V-الخطوة السابعة(Define): هذه الخطوة الإضافية يتم بدء العملية مرة اخرى مع فهم

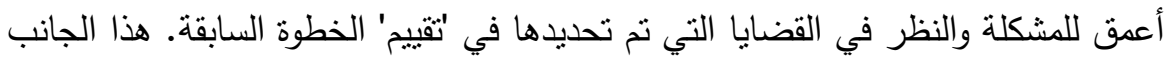

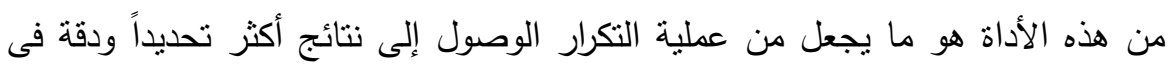

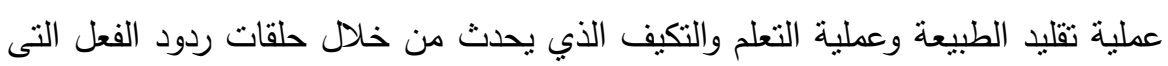
تنكرر 
مجلة العلوم البيئية

معهد الدراسات والبحوث البيئية - جامعة عين شمس لئه

جدول(1) : يوضح اتجاهات عدسة التصميم وفقا للطبيعة البيولوجية

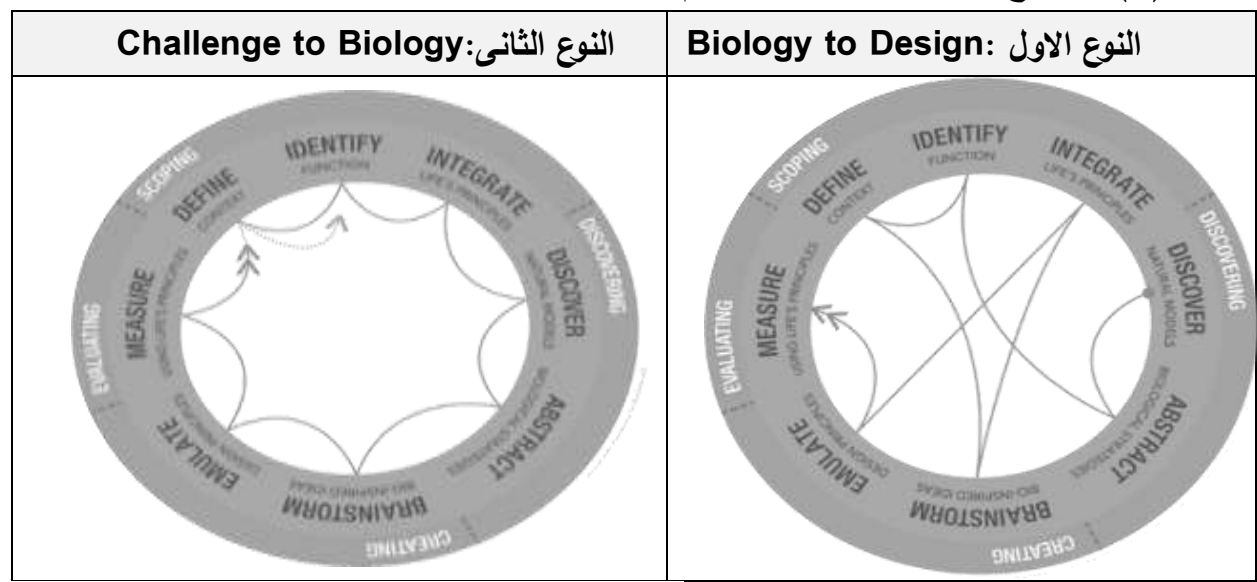

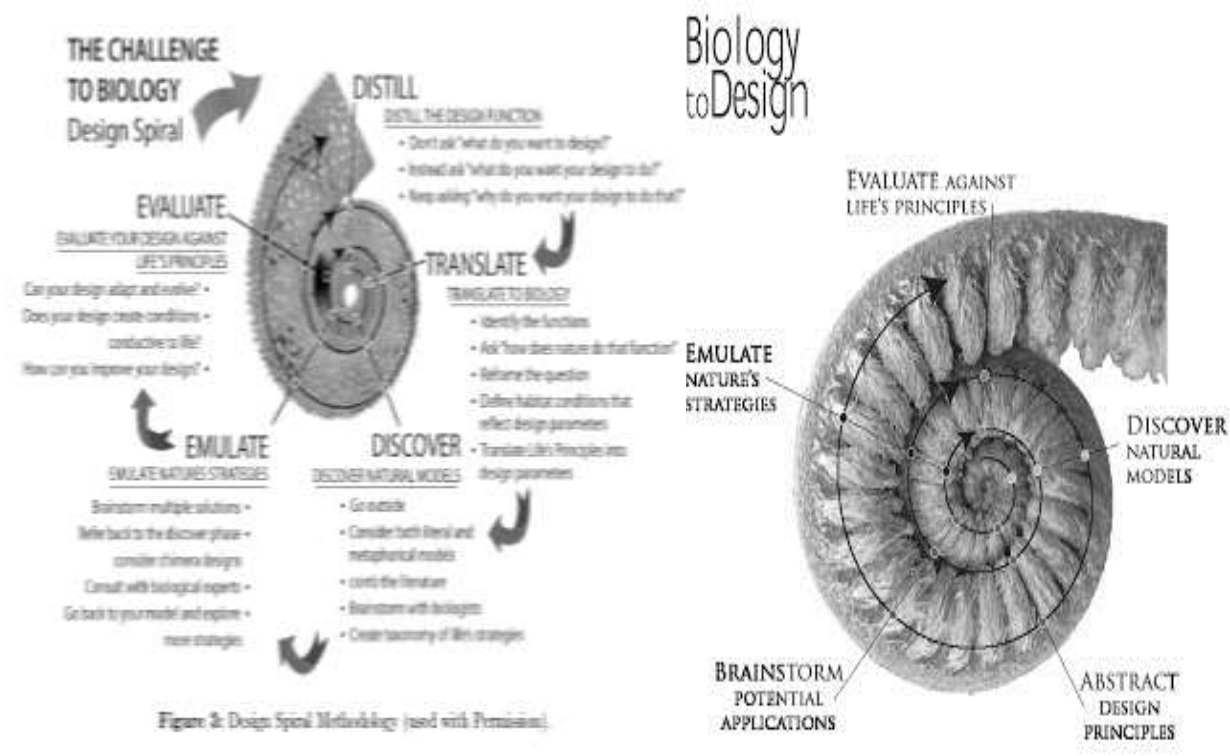

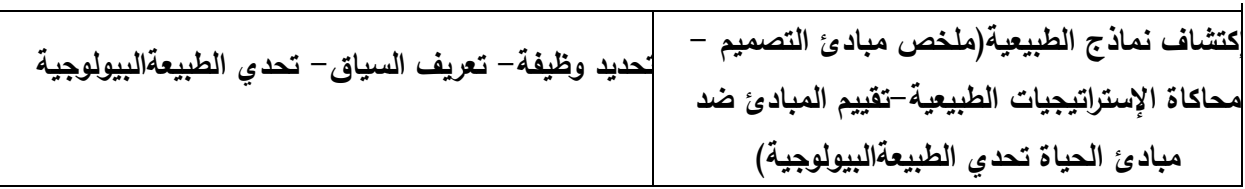

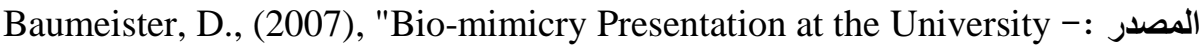
. Seattle, USA.rof Washington College of Architecture" 96

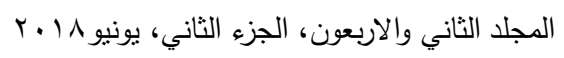


ع) مستويات التصميم المحاكى للطبيعة: من خلال تصنيف الطبيعة لثلاث مستويات يقدر الإنسان أن يحدد حيوية الطبيعة، وكيفية محاكاتها وهم (الكائنات الحية سلوك الطبيعة-النظام الأيكولوجى). وداخل كل من هذه المستويات خمسة أبعاد لتقليد الطبيعة فقد تكون المحاكاة البيولوجية من حيث (الثكل، مواد البناء، كيفية البناء إنشائيا، ونفس ودن لهنه العملية التى تقوم بالطبيعة، أن التصميم قادر على القيام بنفس الوظيفة).

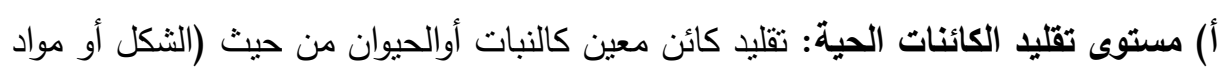

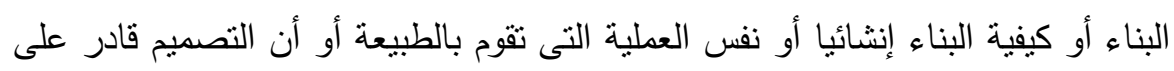

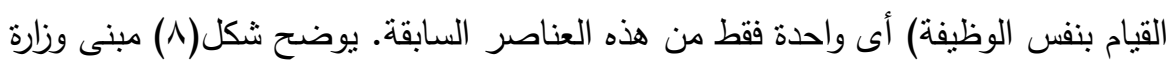

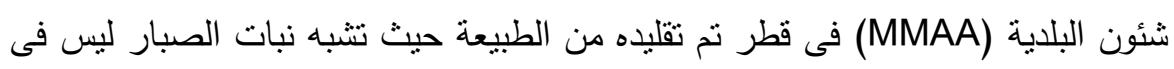
الثنكل وإنما فى وظيفة الصبار فى طريقتها للبقاء على قيد الحياة بنجاح فى البيئات الحارة والجافة وكيفية التعامل مع المناخ الصحراوى. وجعل البرج مستدام بشكل موفر للطاقة

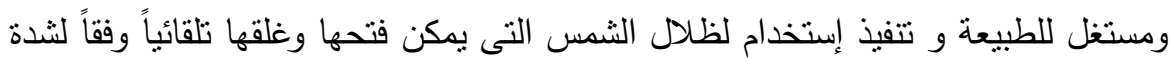
أثنعة الثمس أثناء النهار لحماية من الحرارة فهذا مماثل لكيفية إختيار الصبار لأداء النتح

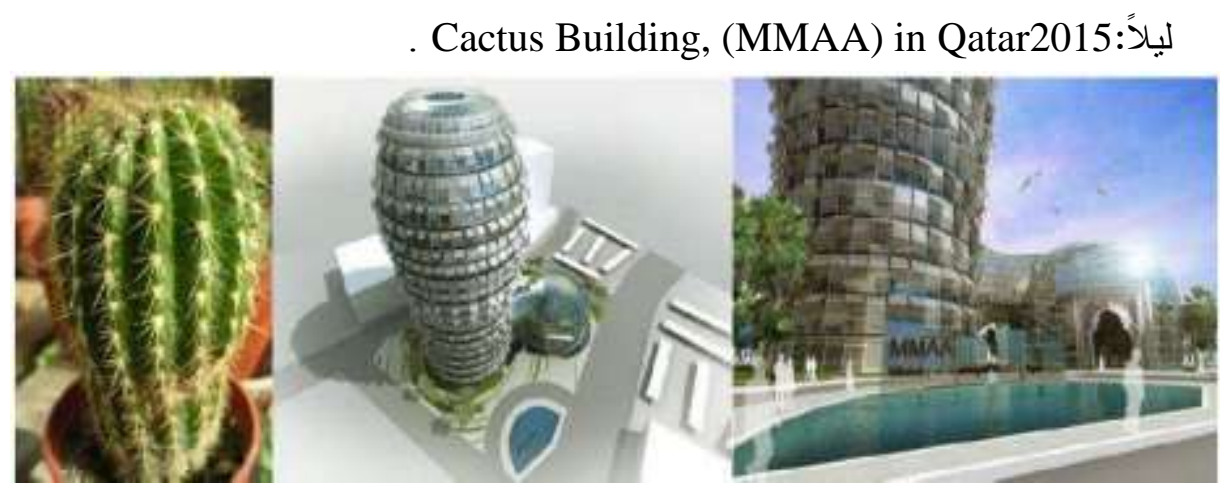

شكل(^): يوضح مبنى وزارة شئون البلدية المستوحى من الصبار

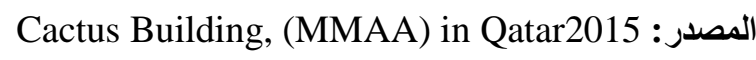

\section{ب) مستوى سلوك (لطبيعة}


محاكاة سلوك الكائنات الحبة فتعتمد على الوظائف وعلاقات الربط من حيث ( الثكل - مواد البناء- الإسلوب الإنشائى -الوظيفة)، يوضح شكل(9) مركز إيستجيت هراري بزيمبابوي

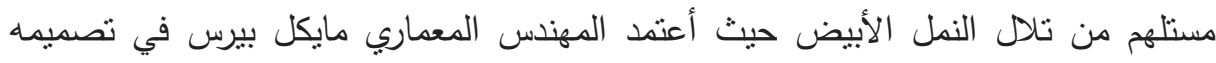
على تصميم أكمات النمل الأبيض إذ تتم تهوية مبنى إيست جيت وتبريده وتدفئته بالكامل

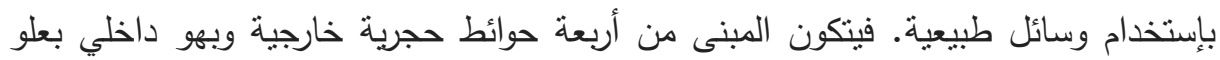
سبعة طوابق. ويتم سحب الهواء الخارجي إلى الداخل عبر العديد من فتحات التهوية ثم يتم إما تبريده أو تدفئته عبر كتلة المبنى حسب أيهما أكثر سخونة، خرسانة المبنى أم الهواء،

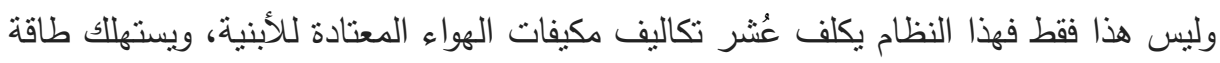

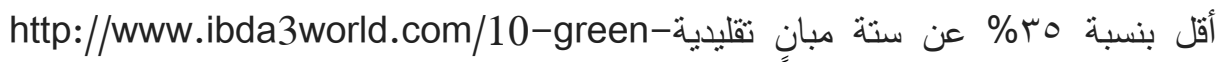
. structural-engineering-marvels

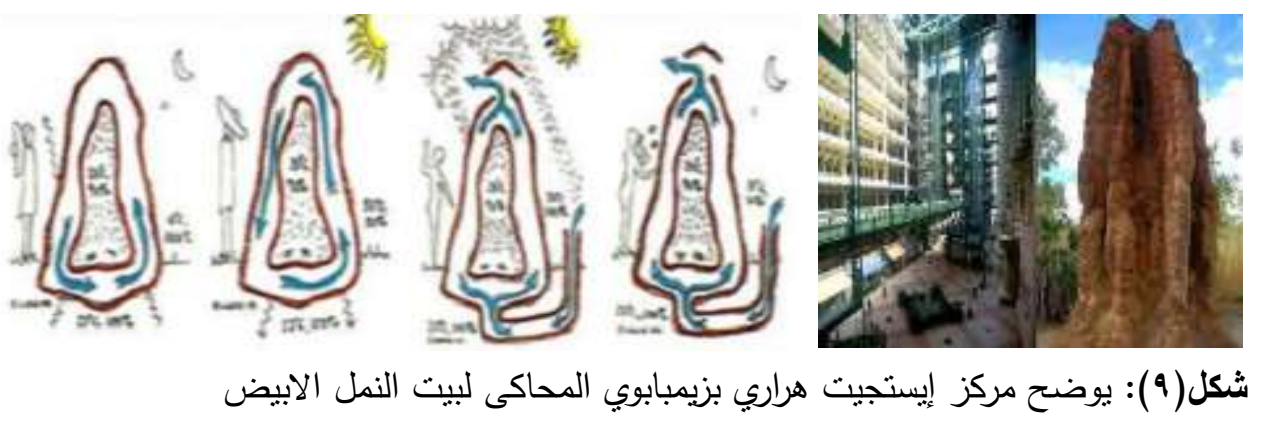

http://www.ibda3world.com/10-green-structural-engineering-marvels :المصدر ج) مستوى تقليد النظام الايكولجى للطبيعة: هي جزء لا يتجزأ من تقليد الطبيعة كما وصفها

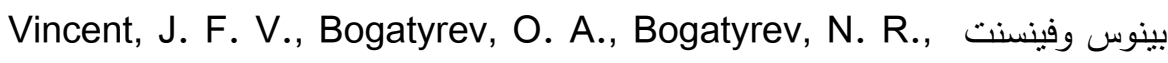
Bowyer, A. \& Pahl, A.-K. , April(2006)," Biomimetic - its practice Journal of the Royal Society Interface ،and theory" مشكلة التصميم ويوضع الحلول من أداء تغيرات الطبيعة من حيث الوظائف والعمليات علي والحلول الماضية، ثم محاكاة مبادئ عبقرية الطبيعة التي هي ذات الصلة لمشكلة التصميم

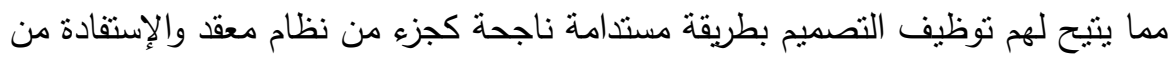

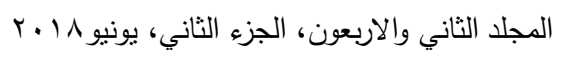


العلاقات بين العمليات المختلفة في الطبيعة وبالتالي الوصول لأسس للنظام البيئي بأكمله، فيهدف مستوى النظام البيئي لتقليد الطبيعة إلى الدمج مع الطبيعة على أساس ستة مبادئ

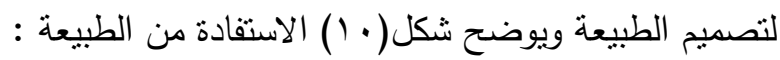
• تشييد بإستخدام المواد المعاد تدويرها والرمل والطين (المواد المحلية). ه التدفئة والتتبريد: من الثمس والأرض.

حصاد المباه: حصول الأسطح على المطر والندى محاكاة ناميبيا خنفساء الجسم. الكهرياء المتجددة: يتم تخزين الطاقة الثمسية وطاقة الرياح لإنتاج الطاقة الكهربائية.

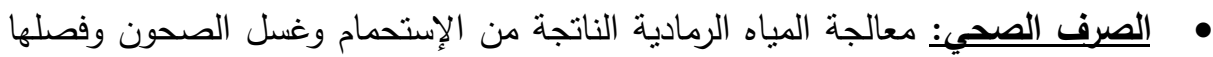
عن المياه السوداء من الحمام ثم يعاد إستخدامها فى رى النباتات والمراحيض. • إنتاج الغذاء: ينتج الغذاء من زراعة النباتات النى تروى بالمياه الرمادية التى تم معالجتها.

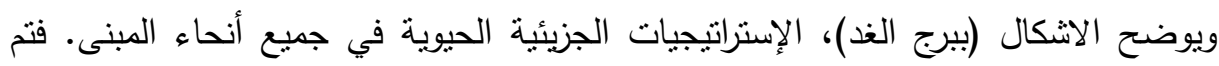

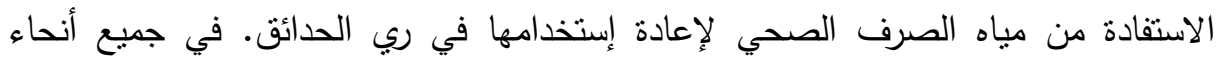
طوابق. فتم تصميم المنحنيات بكامل حجم المبنى وجعل أكثر فتحات هوائية للفراغ المحيط بكفاءة لتجنب تكاليف البناء المفرطة وتتكون الواجهة الجنوبية بأكملها من ألواح الخلايا

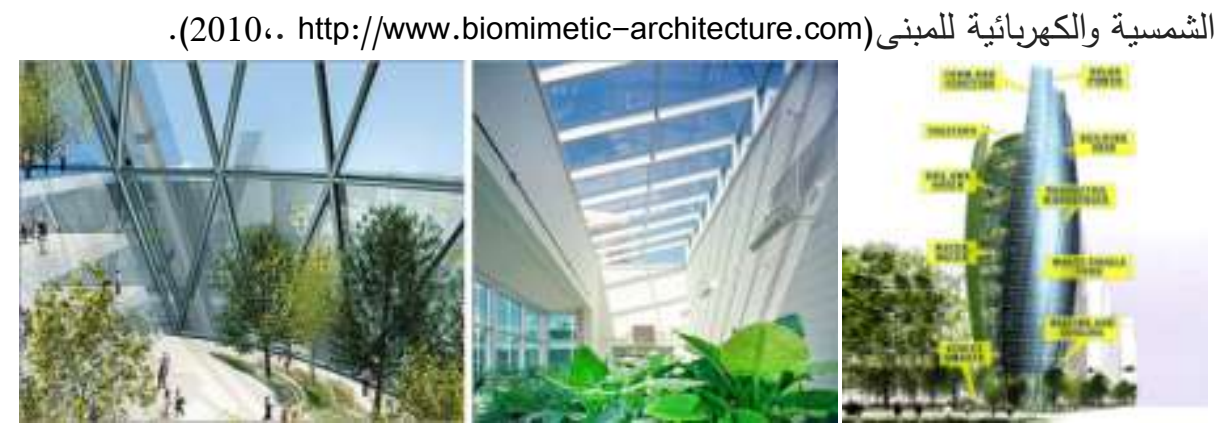

شكل(• (1): William McDonough's Tree scraper Tower of Tomorrow http://www.biomimetic-architecture.com/2010/william-

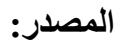
mcdonoughstreescraper/ من الاراسة النظرية السابقة: لإدراك الإنسان لمحاكاة الطبيعة والتعرف على أهم مبادئها

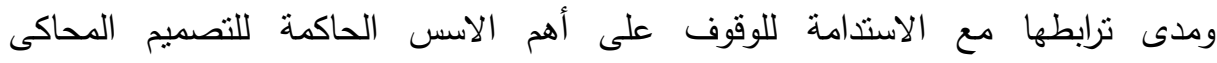

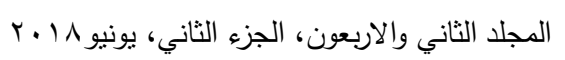


للطبيعة.واستطاع الباحث إستتباط أهم المستويات والمعايير التصميمية التى تحاكى الطبيعة ذات التأثير الإيجابى على إستدامة العمارة.

من ثم سيتم تصميم نموذج لتقبيم وقياس مدى محاكاة الطبيعة وتأثيرها على استخامة العمارة وتطبيقها على مشروعين معمارين لهما نفس الفكر الحاكم، نطبيقأ على البيئة العربية: •) حساب المتوبط النسبى لنتيجة التقييم: • ثابت أساسى لتفاعل المبنى مع البيئة المحيطة ويمثل النسبة الكبرى فى نوذج التقييم .$\%$. • إختبار ثابت من ثلاث متغيرات تمثل المستويات الأساسية للتصميم المحاكى للطبيعة ويمثل · ؛\%، كما هو موضح بجدول(r). 
حسن أحمد حسن يوسف وآخرون

جدول(ץ):

\begin{tabular}{|c|c|c|c|c|}
\hline \multicolumn{2}{|c|}{ نسب التقييم } & \multicolumn{2}{|c|}{ جدول (Y) يوضح نموذج القياس المقترح لقياس محاكاة الثكل بالطبيعة } & \multirow{6}{*}{ الكائنات } \\
\hline \multirow{5}{*}{$\% \varepsilon$. } & $\% \wedge$ & الشكل يشبه شكل كائن حى & 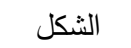 & \\
\hline & $\% \wedge$ & المبنى يصنع من نفس مادة الكائن الحى لنتير للكائن الحى & مواد البناء & \\
\hline & $\% \wedge$ & 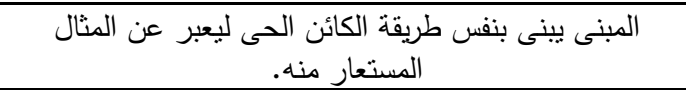 & 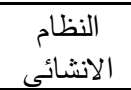 & \\
\hline & $\% \wedge$ & المبنى يعمل بنفس طريقة انقسام الكائن الحى فيشير لهذا & العملية & \\
\hline & $\% \wedge$ & وظيفة المبنى نتبه الكائن الحى فى عمق تكوينه & 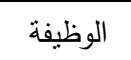 & \\
\hline \multirow{5}{*}{$\% \varepsilon$. } & $\% \wedge$ & المبنى بيشبه طريقة بناء الكائن الحى لمنزله & الثكل & \multirow{5}{*}{ تقليد سلوك الطبيعة } \\
\hline & $\% \wedge$ & المبنى ينشأ من نفس مادة الكائن الحى لنشير للكائن الحى & مواد البناء & \\
\hline & $\% \wedge$ & المبنى يتم انثائه بنفس طريقة الكائن الحى فى طريقة الانشاء & الانظائي & \\
\hline & $\% \wedge$ & 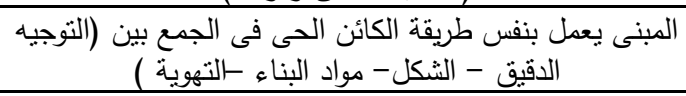 & العملية & \\
\hline & $\% \wedge$ & وظيفة المبنى تشبه بالطريقة نفسها الوظيفة التى تتم بالكائن & الوظيفة & \\
\hline \multirow{5}{*}{$\% \varepsilon$. } & $\% \wedge$ & المبنى يشبه النظام الايكولوجى (يشبه حياة الكائن المستعار ) & الثكل & \multirow{5}{*}{ الايكولوجى النظام } \\
\hline & $\% \wedge$ & 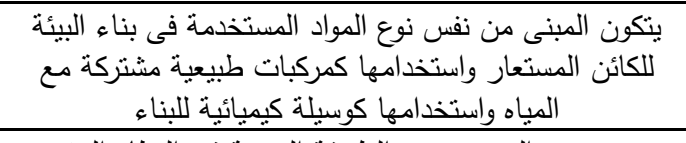 & مواد البناء & \\
\hline & $\% \wedge$ & 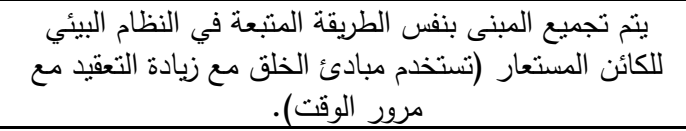 & الانشائى النظام & \\
\hline & $\% \wedge$ & 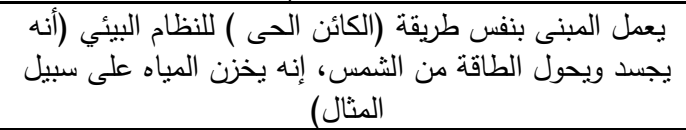 & العملية & \\
\hline & $\% \wedge$ & المستعار) فى النظام البيئي وهذا يشكل جنى الطريقة التي تعمل بهام بيئي (الكعقد. & الوظيفة & \\
\hline \multirow{3}{*}{$\% 4}$. & $\% r$. & التكيف مع الظروف المتغيرة & & \multirow{3}{*}{ التفاعل مع البيئة } \\
\hline & $\%$ \%. & ترشيد استهلاك الطاقة & & \\
\hline & $\% r$. & \multicolumn{2}{|c|}{ استخدام الاساليب التكنولوجية الحديثة التى تعمل على استدامة العمارة } & \\
\hline
\end{tabular}

ثانياً: اختيار عينات الدراسة: ينم إختيار العينات من حيث عدة نقاط:

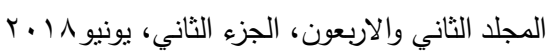


• سماتها الثكلية الظاهرة مرتبطة بمحاكاة الطبيعة.

• ان تحقق المبانى مبادئ العمارة البيئية.

• نتخدم التكنولوجيا الرقمية فى المعالجات البييئية والاشكال الطبيعية.

• ان تتدرج هذه المبانى فى فترة زمنية محددة خلال عشر سنوات سابقة.

• تكون عينات المشروع على المستوى الإقليمى(البيئة العربية).

جدول(ب): يوضح تحليل عينات الدراسة

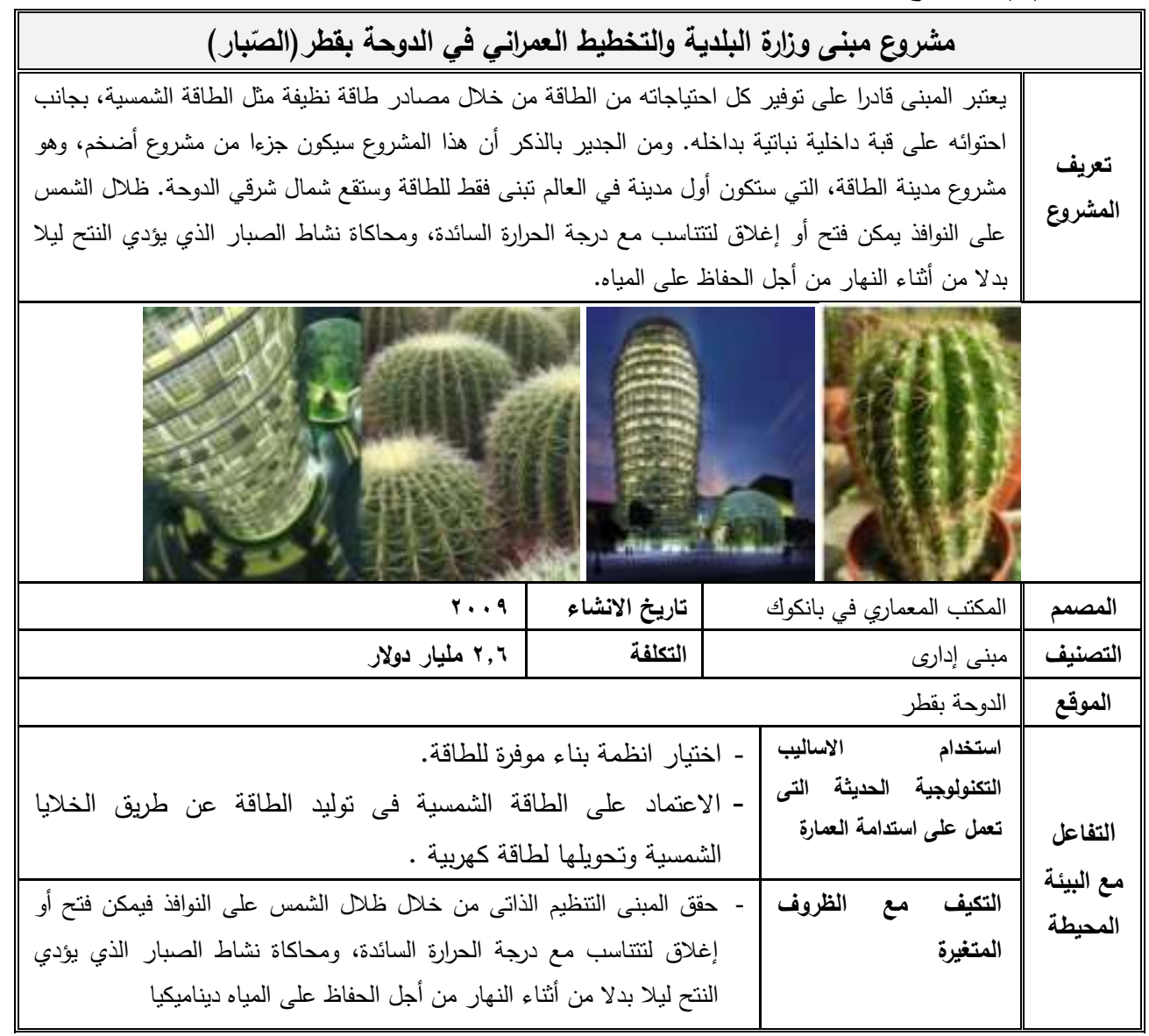


حسن أحمد حسن يوسف وآخرون

\section{تابع: جدول(ץ): يوضح تحليل عينات الدراسة}

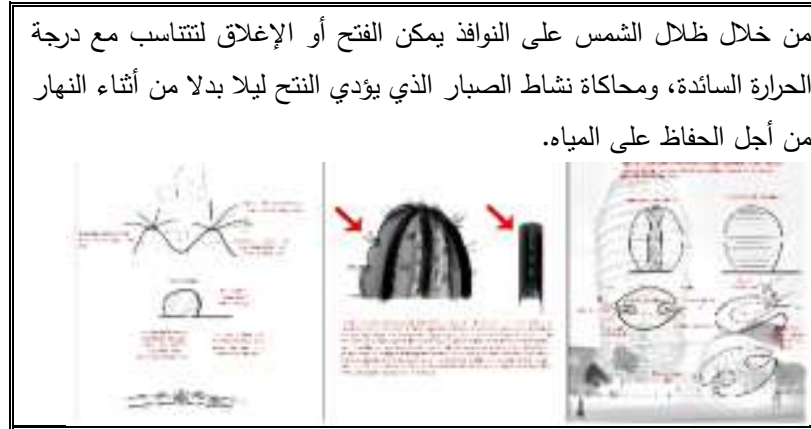

- النظام الانشائى: يحاكى نبات الصبار فى الثكل ويطبق فى هيكل المبنى

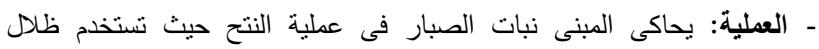

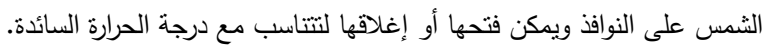
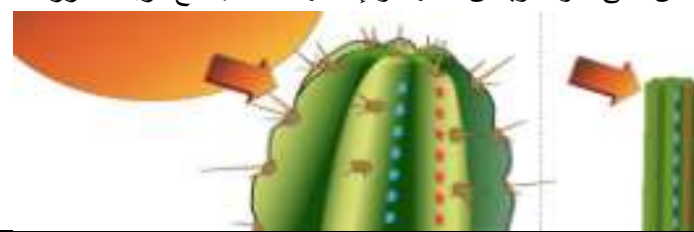

ترشيد استهلاك الطاقة

\section{المشروع الثانى:- BUSSNIES- BARK}

اعتمدت الفكرة التصميمية للمشروع على امتداد تأثير المشروع من الأطار المعمارى لمبنى ادارى مستقل الى الاطار

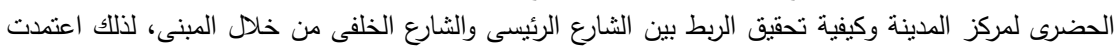

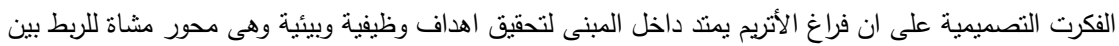

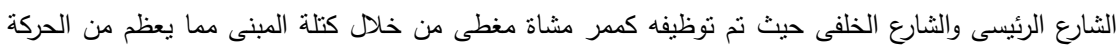

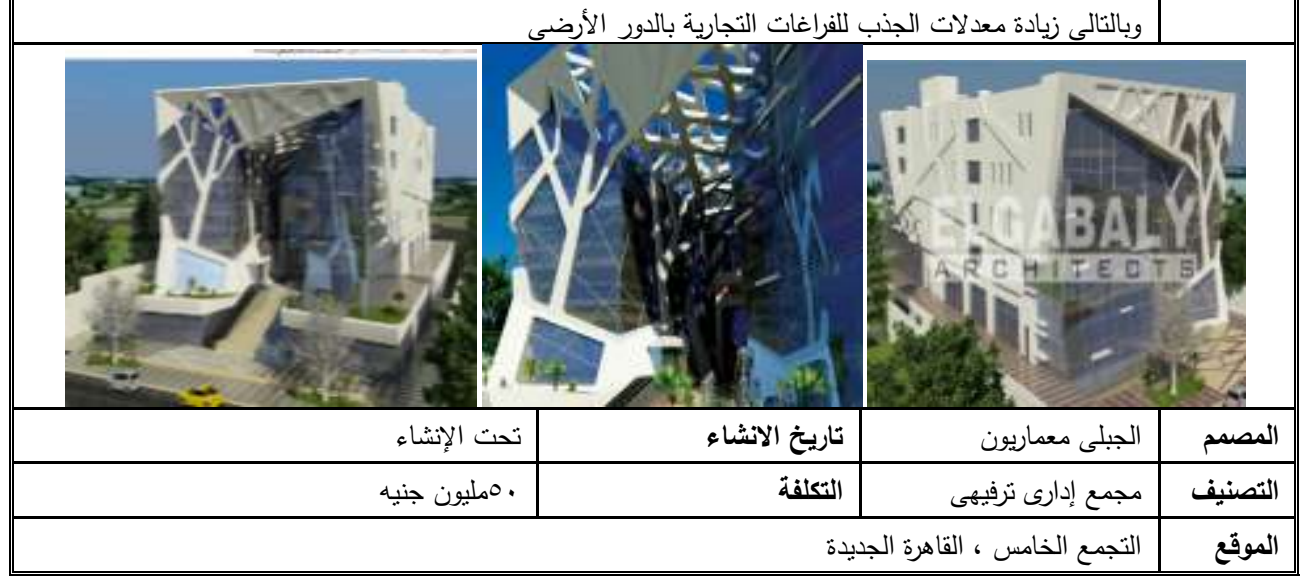

تابع جدول(r): يوضـح تحليل عينات الدراسة

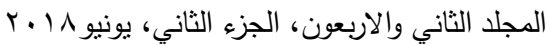


مجلة العلوم البيئية

معهد الدراسات والبحوث البيئية - جامعة عين شمس لهن

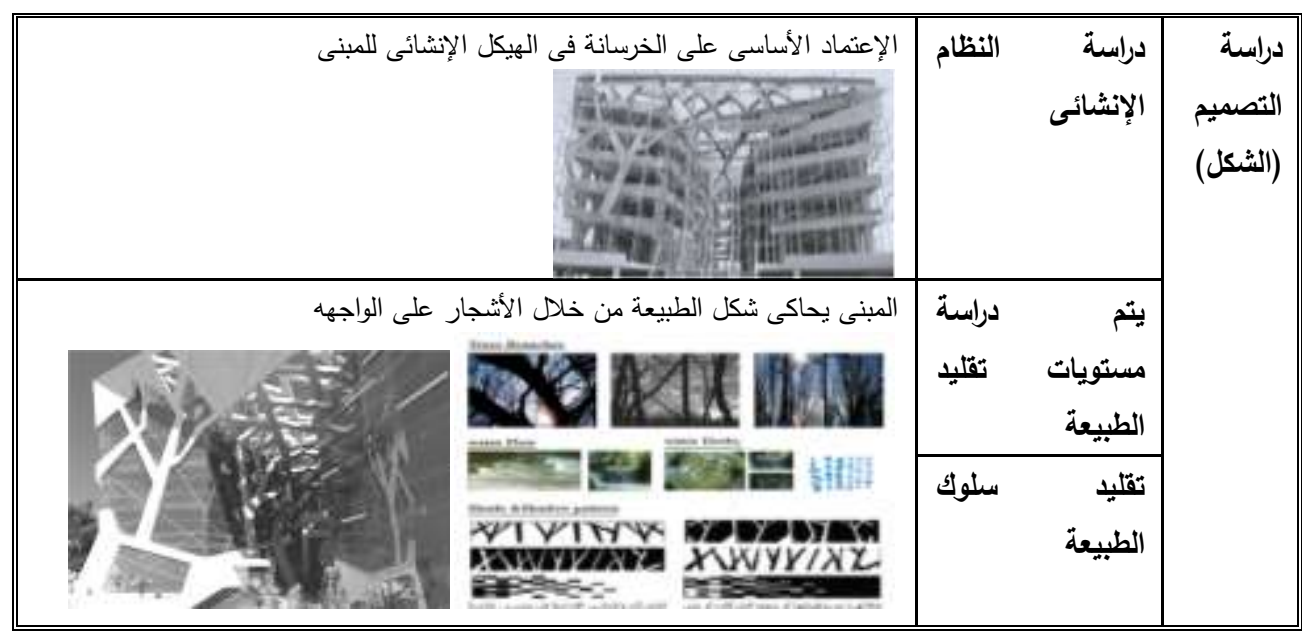

المصدر: الباحث 
حسن أحمد حسن يوسف وآخرون

جدول(ع): معايير القياس لعينات الدراسة

\begin{tabular}{|c|c|c|c|c|c|c|}
\hline المحور تلأثير & الثشروع & الاول المشوع & \multicolumn{3}{|c|}{ معايير القياس المستتبطة من الجزء النظرى } & \\
\hline \multirow{10}{*}{$\%$ \%० } & $*$ & * & الشكل يشبه شكل كائن & الثنكل & \multirow{5}{*}{ الكائنات } & \multirow{10}{*}{ الاولتول الطقيد } \\
\hline & - & - & 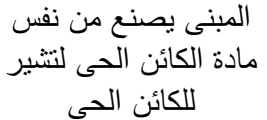 & المستخدمة البناء & & \\
\hline & - & * & 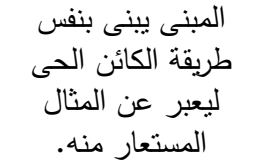 & الانشائى النظام & & \\
\hline & - & * & الققسام الكائن الحى بنى فيشير طريقة & العملية & & \\
\hline & - & - & الكائن الحى فئى المبنى تشبه عق & الوظيفة & & \\
\hline & - & - & المبنى بيشبه طريقة بناء الحئ لمنزله & الثكل & \multirow{5}{*}{ سلوتيد } & \\
\hline & - & - & مادة الكائن الحئن لتشيرأ من نفس & المواد البناء & & \\
\hline & - & - & 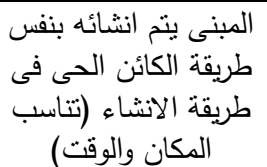 & الانشائى النظام & & \\
\hline & - & - & 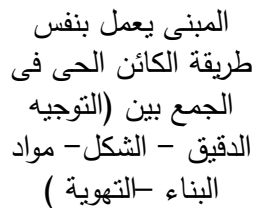 & العملية & & \\
\hline & - & - & 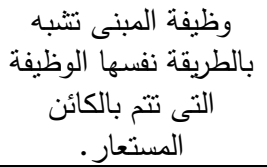 & الوظيفة & & \\
\hline
\end{tabular}

تابع: جدول(؟) : معايير القياس لعينات الدراسة

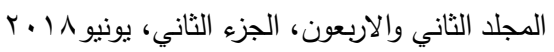


مجلة العلوم البيئية

معهد الدراسات والبحوث البيئية - جامعة عين شمس لئه

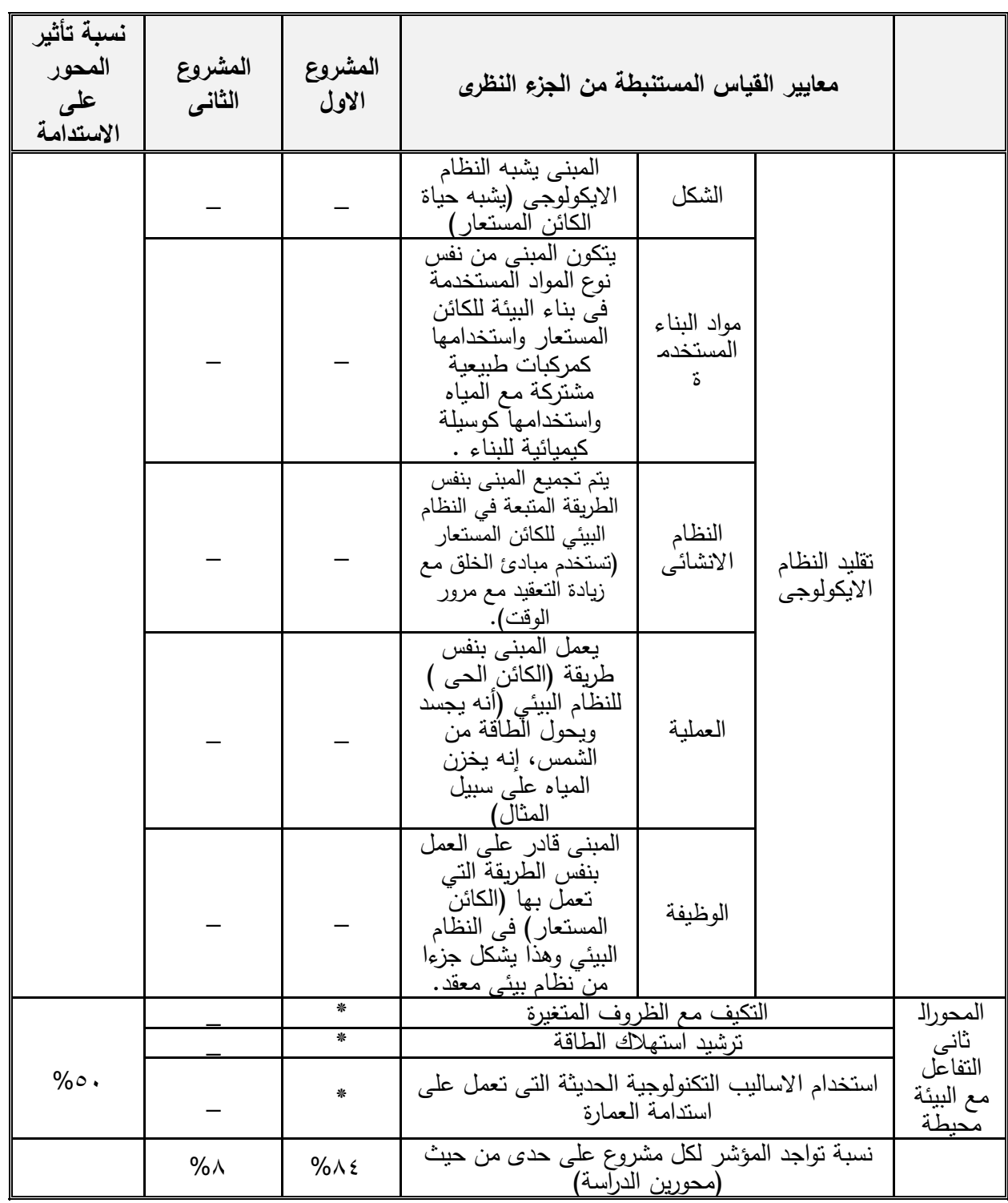

لمصدر: الباحث 
نتيجة للتحليل المقارن بين المشروعين (مبنى الصبار)، (BUSSNIES BARK ) فقد

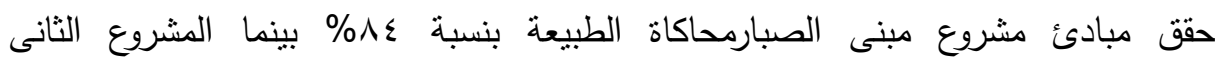
BUSSNIES BARK حقق مبادئ محاكاة الطبيعة بنسبة ^^\%ما هو موضح بالرسم البيانى الاتى:

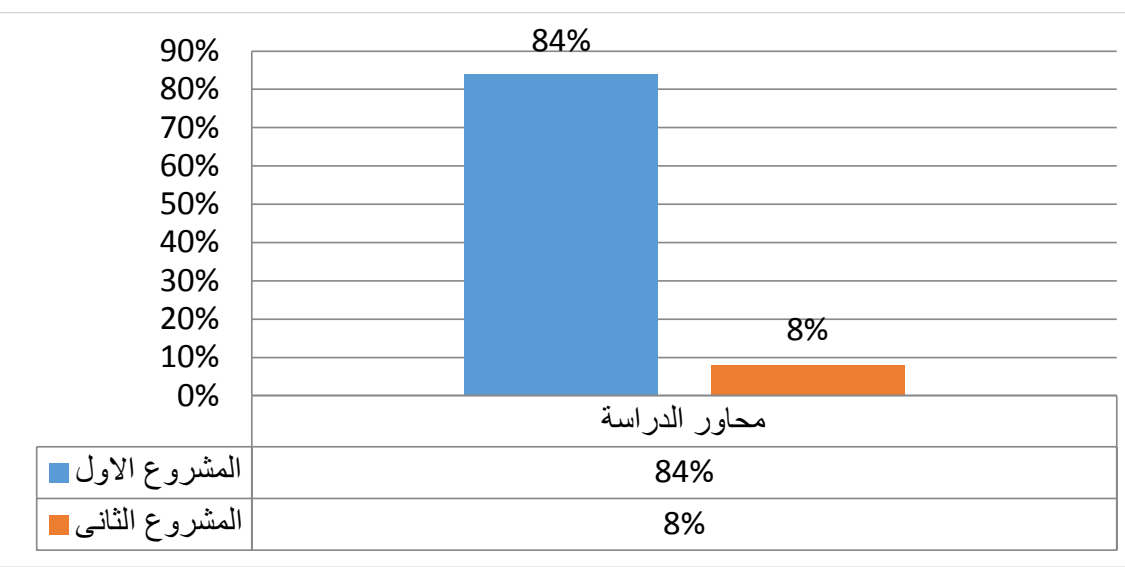

شكل(1 1 ()): النسب المئوية لنتيجة التحليل المقارن لعينات الدراسة. المصدر : الباحث

وقع مبادئ المحاكاة على محوريين رئيسيين فى الجدول: الأول مسنويات تقليد الطبيعة

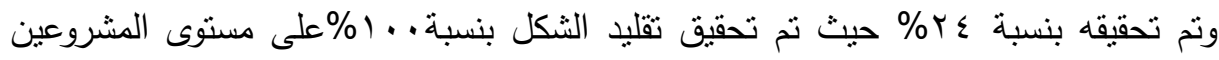

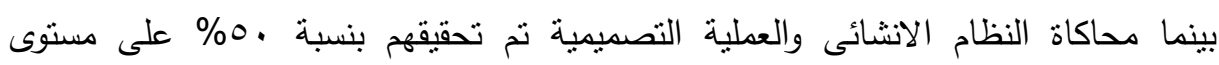

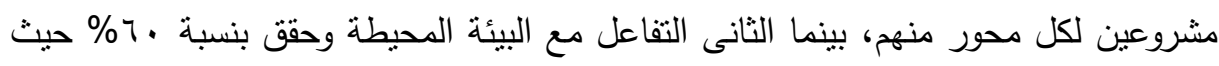

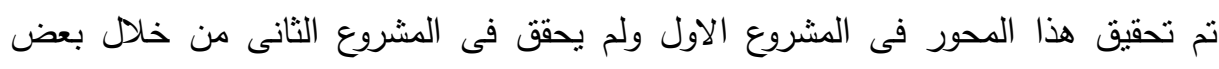
العناصر كالتكيف مع الظروف و ترشيد استهلاك الطاقة و استخدام الاساليب التكنولوجية

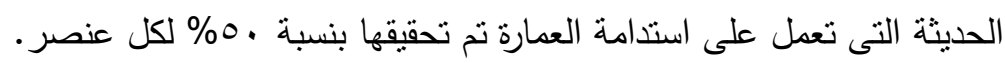


مجلة العلوم البيئية

معهد الدراسات والبحوث البيئية - جامعة عين شمس له

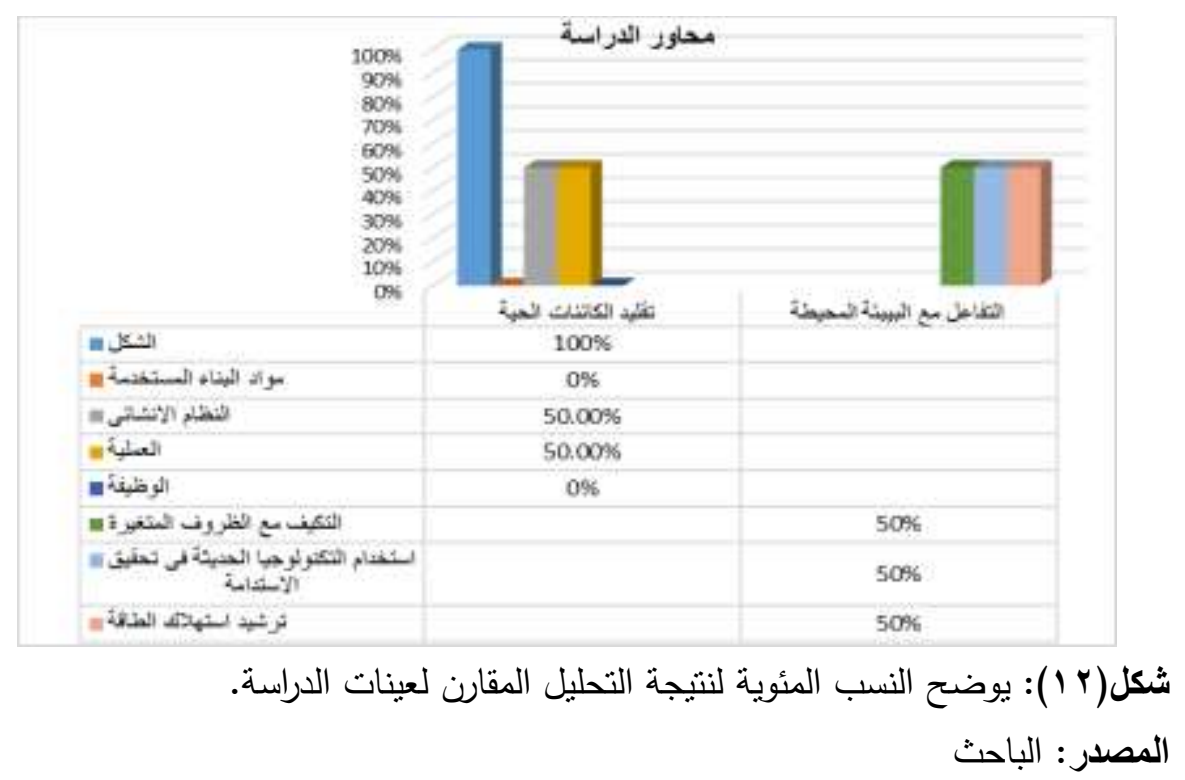

مما سبق ذكره نستتتج أن المشروع الثانى قام بتقليد الثكل دون مراعاة الوظيفة الحيوية

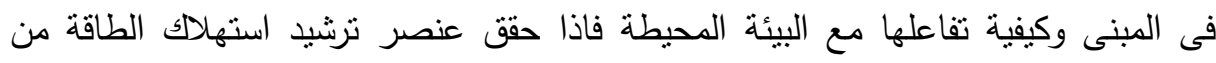
خلال تغطيات الخارجية واستخدام الاساليب التكنولوجية الحديثة للتكيف مع الظروف المتغيرة كان من الممكن ان يحاكى الطبيعة كما قال وليس تقليد.

\section{المنيأئ.}

1. اعتماد عمارة محاكاة الطبيعة على خلق الظروف المثالية بين الانسان والبيئة المحيطة. r. إندماج الاشكال المستتبطة من الطبيعة المحيطة فى خلق بيئة عمرانية تحاكى الثكل والوظيفة.

r. حققت عمارة محاكاة الطبيعة التفاعل مع البيئة المحيطة فى تحقيق النوازن بين التفاعلات والتغيرات للعلاقات المتبادلة التى شملت الانسان بإمكانياته دون الاخلاد بالموارد

$$
\text { والامكانات الطبيعية. }
$$

ء. اعتمدت محاكاة الطبيعة على أخذ الشكل من الطبيعة مع القدرة على تتفيذ الوظيفة.

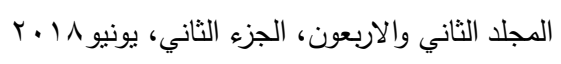


ه. بالرغم من ارتفاع التكلفة النظرية للمبانى المصممة بفكر عمارة محاكاة الطبيعة أثناء عمليات

7. التصميم والانشاء إلا أنها تعتبر إقتصادية لتخيل التصميم وتلافى حدوث أخطاء ومشاكل

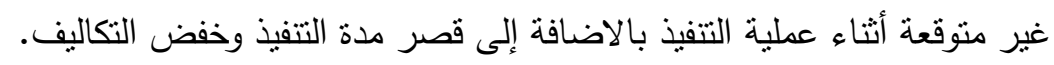

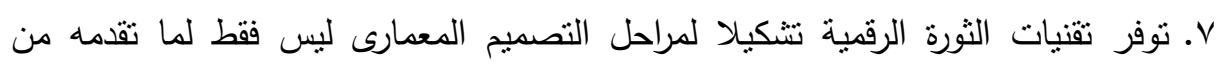

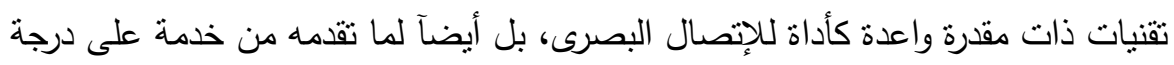
عالية من الأهمية والفاعلية يمكن فهها على أنها فرصة للنتغبل التجربيى بإستخدام تقنيات الواقع الافتراضى والمحاكاة وذلك لكى يختبر المعمارى تصميمه.

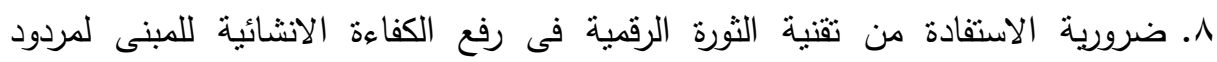
الاستفادة منها فى العملية التصميمية.

9 9. التكامل بين تكنولوجيا الثورة الرقمية والتصميم المعمارى وتكنولوجيا البناء هو الضلىع الرابع

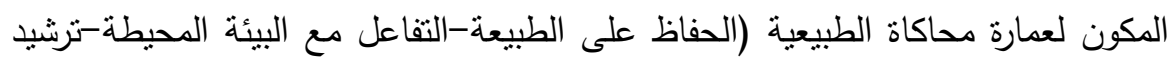
استهلاك الطاقة-استخدام مصادر الطاقة المتجددة).

• . . من خلال البحث تم قياس درجة محاكاة الطبيعة لبعض المشروعات فى البيئة العربية وقد نم إثبات وصول هذه المشروعات لتحقيق واقعها الزمانى والمكانى من خلال

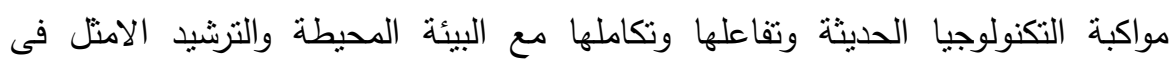
استخدام الطاقة الغير متجددة واستخدام مصادر الطاقة البديلة وتقنين استخدام الموارد للمحافظة على التجدد والاستدامة على غرار ما يحدث فى الطبيعة.

\section{التحوسياهي}

لكى يتم تحقيق اقصى كفاءة للاستدامة بالمبانى عن طريق تأثر الثكل لمحاكاة الطبيعة سيتم طرح التوصيات على أربع مستويات أساسية للوصول إلى بيئة عمرانية مستدامة تحتوى بلى باتئي على مبانى تحاكى الطبيعة.

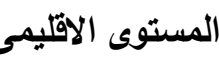


•لابد لسياسات الدول العربية أن تضع سياسات وتتريعات لحماية البيئة والإهتمام بالأحزمة الخضراء حول المدن وحماية الزراعة والمناطق الخضراء مع سن قوانين حاسمة بشأن النلوث والتخلص من النفايات.

• مراعاة تشكيل المدن العربية الجديدة لتكون تجمعات عمرانية متوازنة داخليا تتكامل بهات ماتهات

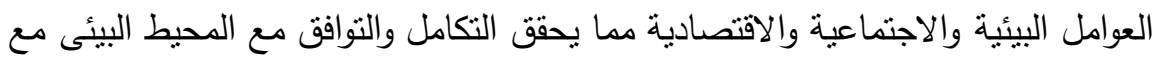
مراعاة إضفاء الانتماء النقافى والاجتماعى. • إتباع مدخل التصميم البيئى المتكامل لتتمية المدن المستقبلية لتحقيق مجتمعات مستدامة إهاءة تحقق الأهداف التخطيطية وذلك عن طريق إحياء فكرة استتباط الاشكال من محاكاة

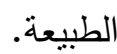
• النمو العمرانى الجديد والأسس التصميمية لابد أن تكون محكومة عن طريق قوانين وتنشريعات. • إهتمام البلديات والمحليات بزراعة الأثجار فى المدن لتتقية الهواءو و المحافظة على البيئة. • ضرورة الاستفادة من الجوانب المرتبطة باستراتيجية محاكاة الثكل للطبية فى المدينة العربية بهدف الاستفادة من التجارب والخبرات العملية والتصميمية ونتاجلتها الثكلية المتميزة لخلق عمارة متواصلة مع حضارتها. الاستفادة من التجارب العالمية فيما يخص التقنيات والمواد الانشائية والتى توفر امكانية اكبر فى تحقيق عمارة تحاكى الطبيعة .

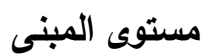
لابد أن يراعى تصميم المبنى العوامل المناخية من حرارة ورياح وأمطار، مع الاهتمام بالإضاءة والتهوية الطبيعية وتشجيع استعمال الطاقة المتجددة لأنظمة التدفئة والتبريد وترشيد استعمال المياه. • الاهتمام بتطبيق الأكواد الخاصة بتوفير الطاقة وترثيدها في المبانى.

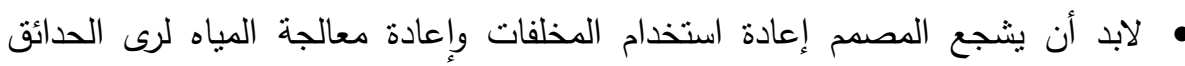
واستعمالات النظافة. 
حسن أحمد حسن يوسف وآخرون

•الاستعانة بالتكنولوجيا الحديثة فى البنية الأساسية للمساكن وربطها الكترونبا بالثبكات

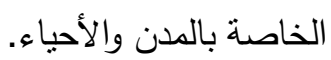

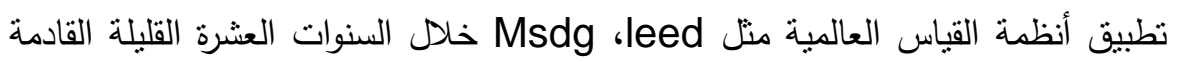

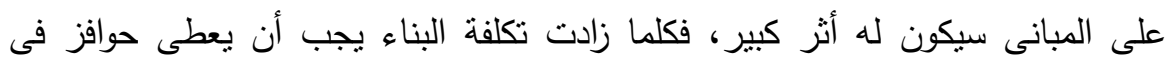
صورة خفض الضرائب وأسعار الخدمات.

مستوى القوانين والتشريعات

هابد من تطوير تشريعات البناء والنظم التحتية وأنظمة الإدارة المحلية حتى تتوافق مع منطلبات المدن المستدامة.

• الاهتمام بان تكون النظم التخطيطية ونتريعات البناء بها من المرونة والقابلية للتكيف بحيث تسنوعب تلأك المقترحات.

اتساع نطاق كودات المبانى لنتمل كل مناحى العمارة لاستيعاب التكنولوجيا الحديثة وسبل توفير الطاقة ومتطلبات العمارة الخضراء.

• لابد من انتشار هذا التوجه فى كافة بلدان الوطن العبى حتى يمكن فى خلال المرحلة

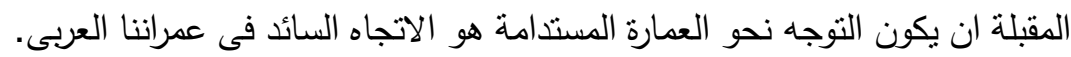

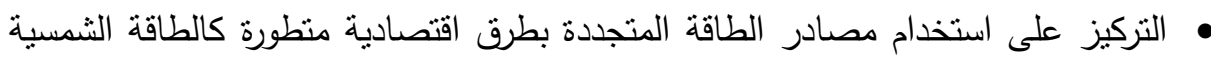
وطاقة الرياح الطاقة الحيوية والطاقة الكهرومائية وطاقة جوف الأرض والاستفادة من تجربة دبى فى البناء الأخضر •

\section{2all}

قاعدة بيانات معتمدة عن ظواهر الطبيعية (AskNature.org)

منظمة دولية للاعوى لمحاكاة الطبيعة(Biomimic.org)

Baumeister,D, (2007): "Bio mimicry Presentation at the University of Washington College of Architecture". Seattle, USA .

Benyus, J. M، (2002): "Biomimicry: Innovation in-spired by nature"، NY: Williams and Morrow.

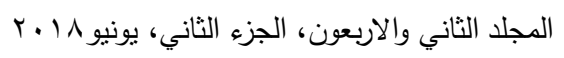


Benyus, M, Janine, (1997): "Innovation inspired by nature" published by Harper Perennial.

Chris W. Scheuer and Gregory A. Keoleian,(2002): Evaluation of LEED Using Life Cycle Assessment Methods, Center for Sustainable Systems University of Michigan, Ann Arbor, MI

http://scienceandquran.com.

Meyers ,Marc André, P.-Y. C. (2015): Biological Materials science:

Biological materials, Bioinspired materials and biomaterials. Cambridge University Press.

Neal Panchuk, (2006): An Exploration into Biomimicry and its Application in Digital \&Parametric [Architectural] Design, Waterloo, Ontario, Canada.

Reap, J., Baumeister, D. \& Bras, B ‘(2005): "Biomimicry and Sustainable Engineering". ASME International Mechanical Engineering Conference and Exposition. Orlando, FL, USA.

Reed, B، "Shifting our Mental Model، (2006): "Sustainability to Regeneration Rethinking Sustainable Construction"،Next Generation Green Buildings. Sarasota, Florida.

Schulz, Christian N.,(1971): "Existence, Space andArchitecture", Prayer Publishers, INC., NewYork.

Vincent, J. F. V., Bogatyrev, O. A., Bogatyrev, N. R., Bowyer, A. \& Pahl, A.-K. (2006): Biomimetics - its practice and theory. Journal of the Royal Society Interface, April

Yedekci Arslan, G. (2014, December): Biomimetic Architecture A New Interdisciplinary Approach to Architecture. NIVERSITI UTRA ALAYSIA Alam Capita vol 7.

Zari, Maibritt Pedersen`(2009): Biomimetic approaches to Architectural design for increased Sustainability. School of Architecture,

$$
\text { المجلد الثاني والاربعون، الجزء الثاني، يونيو \ ـ ب }
$$


حسن أحمد حسن يوسف وآخرون

Victoria University, PO Box 600, Wellington, New Zealand.

\title{
THE SIMULATION OF NATURE EFFECT ON SUSTAINABLE ARCHITECTURE DESIGN
}

\author{
El-henawy M. A. ${ }^{(1)}$ Youssef, H. A. H. ${ }^{(2)}$; Sobh, H. A. M. ${ }^{(1)}$
} and Ibrahim, Gehad, G. ${ }^{(3)}$

1) Department of Architecture, Faculty of Engineering, Al-Azhar University 2) Department of Architecture, Aviation Engineering and Technology Institute 3) Higher Institute of Engineering

\begin{abstract}
The idea of simulating nature and its impact on sustainable design is a useful idea to maintain ecological balance, which is a vital subject in the face of the phenomena that threaten our planet. The research discusses the effect of architectural thought on the simulation of nature and its impact on the sustainability of the urban environment. Which aims to measure and evaluate the simulation of modern environmental projects of nature in the Arab environment through compatibility with the principles and ideas of nature simulation architecture, and then practical application of the evaluation model to measure the nature simulation architecture on some projects The study ends with a comparative analysis of the selected projects in order to identify the most simulated nature and use it as a model for measuring environmental projects in the Arab region.
\end{abstract}

Key words: Nature Simulation - Sustainable Design.

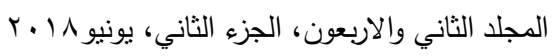

